\title{
ISOLATION OF KLEBSIELLA SPP. FROM SOME MEATS
}

\author{
N. SOULEMAN", A. AL-MARIRI** and I. HAMAD ${ }^{* * *}$ \\ *Plant Biology Department, Faculty of Sciences, University of Damascus, Syria. \\ ${ }^{* *}$ Molecular Biology and Biotechnology Department, Atomic Energy Commession, Syria. \\ ${ }^{* * *}$ Ecology Department, Faculty of Sciences, University of Damascus, Syria.
}

\begin{tabular}{ll}
\hline ABSTRACT \\
\hline \\
Meats often contains micro-organism which may cause disease, \\
Including Klebsiella spp. Which cause wide range of disease \\
states, notably pneumonia, urinary tract infections (UTIs), and \\
bacteremia. The aim of this study was collected 100 samples of \\
meats (Calf, sheep, chicken) from the meats shops present in the \\
different area in Damascus and countryside in a sterile container, \\
for isolated Klebsiella and growing it on Selective Media to \\
identify and characterize its morphology, biochemical and \\
Molecular Characteristics by using Polymerase chain reaction \\
PCR. Colonies of the microorganisms were counted on difference \\
media then isolated from a selective media. The colonies of \\
Klebsiella isolated are circular, dome-shaped. 3-4 mm diameter \\
with mucoid aspect, stickiness and surrounded by capsule. Our \\
results showed that 46\% of examined specimen contained \\
Klebsiella spp. The results showed that it can investigate \\
of Klebsiella in meats samples by biochemical reactions and \\
polymerase chain reaction. In next study we will be produced \\
primers To differentiate between two types of Klebsiella \\
(K. pneumoniae and $K$. oxytoca).
\end{tabular}

Key words: Klebsiella spp., Raw Meats, Biochemical tests, Polymerase chain reaction (PCR).

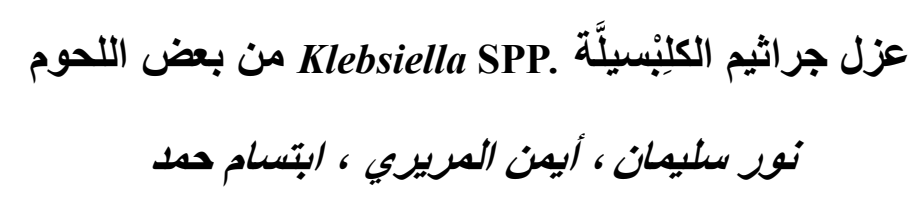

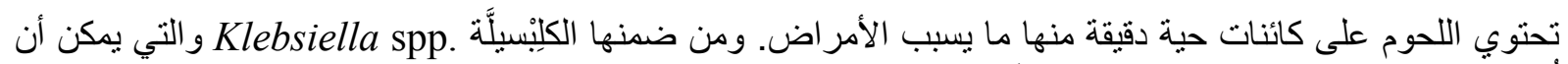

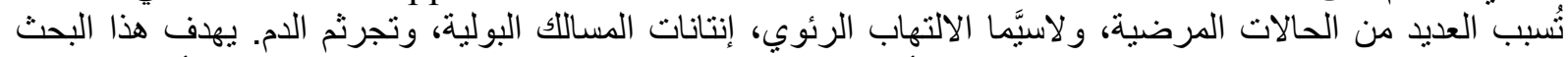

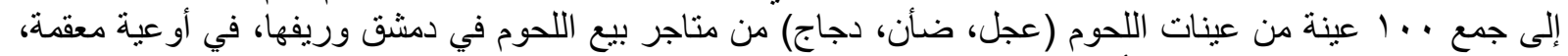

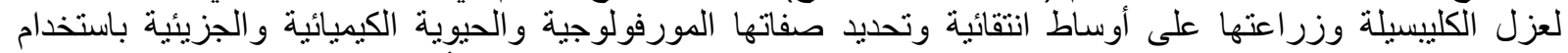

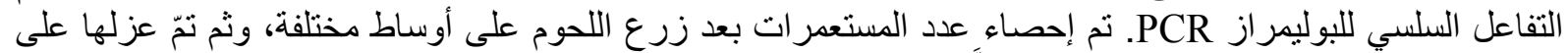

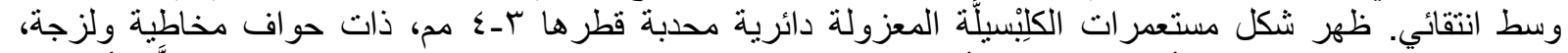

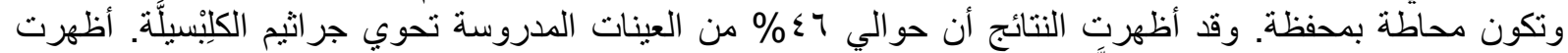

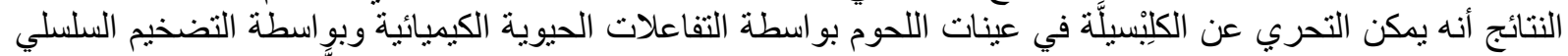

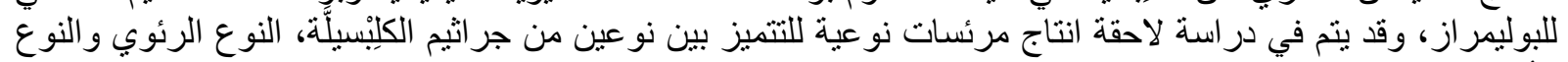
المُعَجل للولادة.

الكلمات المفتاحية: الكِلِبسيَّة، اللحوم، الاختبارات الحبوية الكبيبائبة، التفاعل السلسلي للبوليبيراز PCR. 


\section{INTRODUCTION}

\section{المقدمـة}

تعد اللحوم من أكثر أنواع الأغذية عرضة للفساد بسبب سهولة نمو الأحياء الدقيقة فيها، وخاصة الجراثية الثيم التي

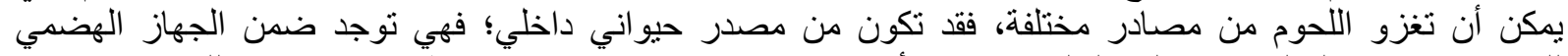

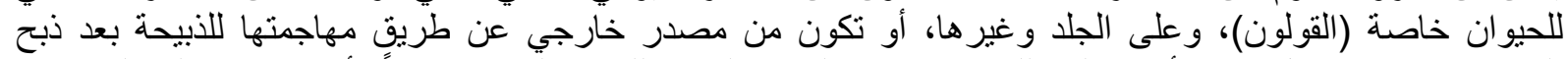

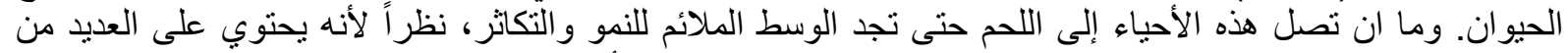

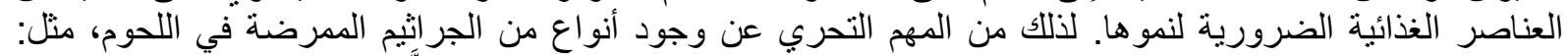

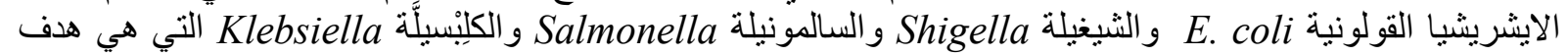

در استنا.

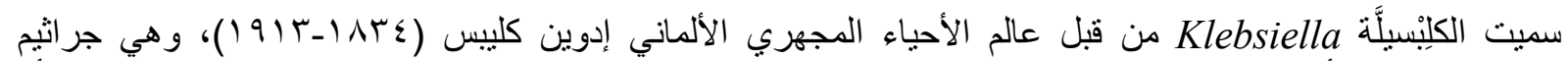

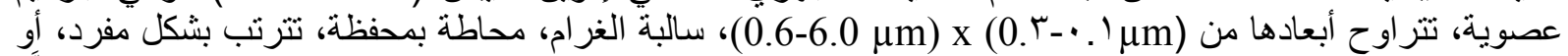

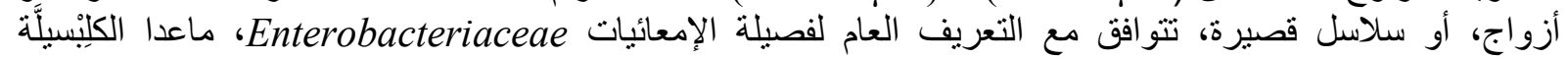

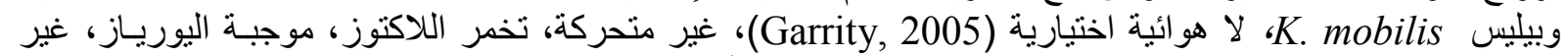

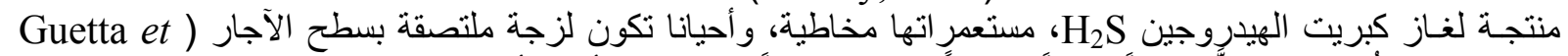

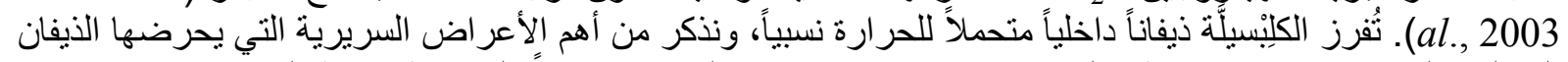

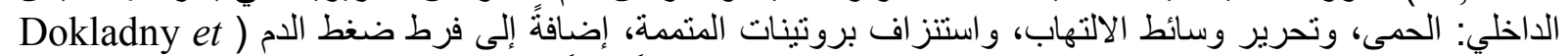

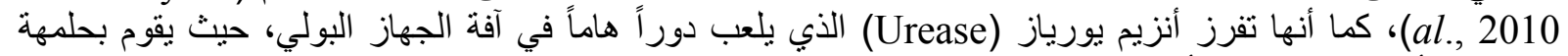

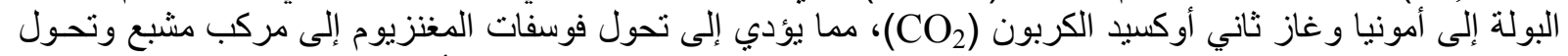

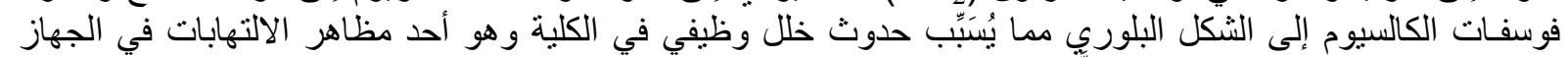

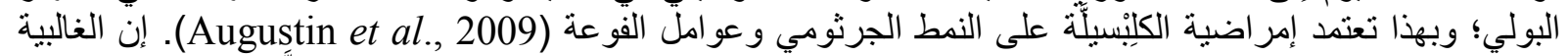

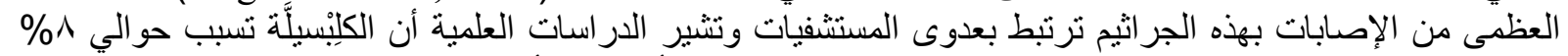

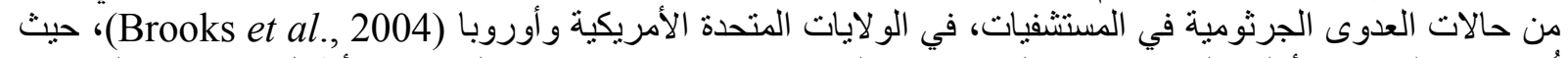

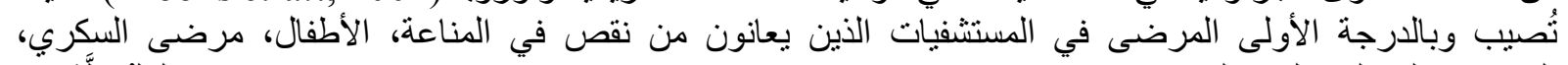

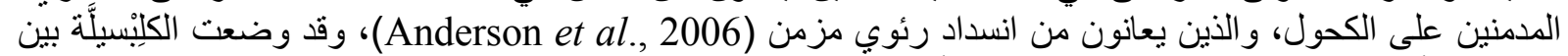

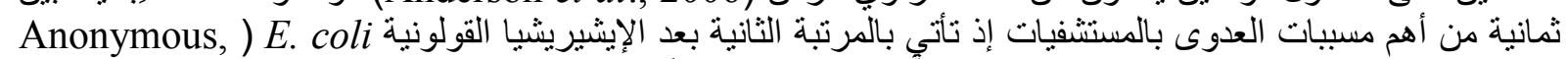

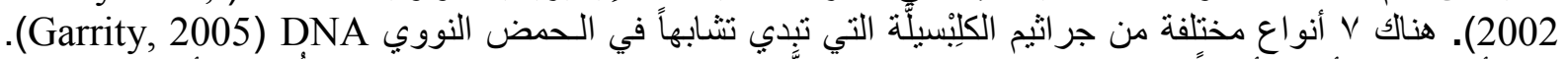

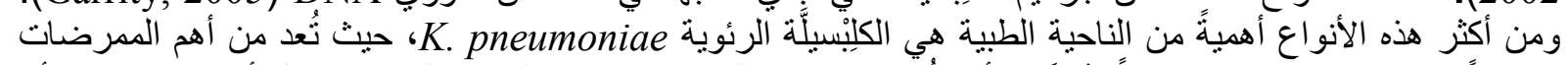

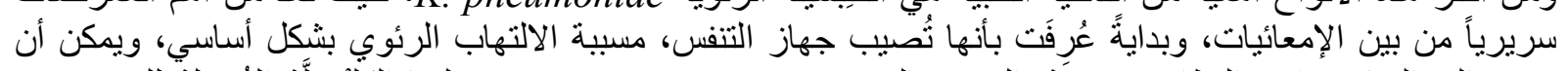

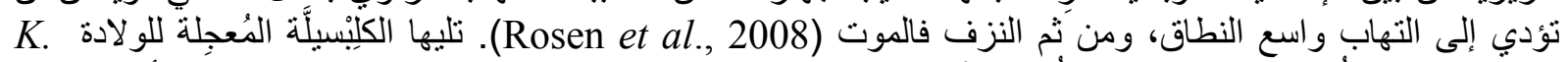
oxytoca

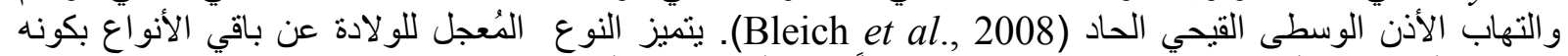

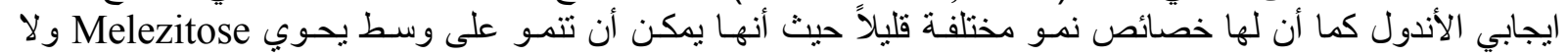

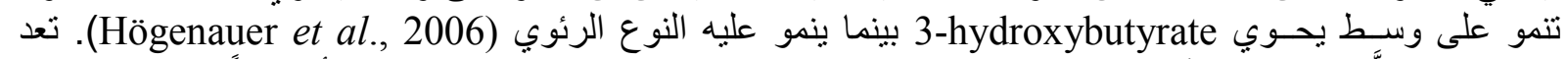

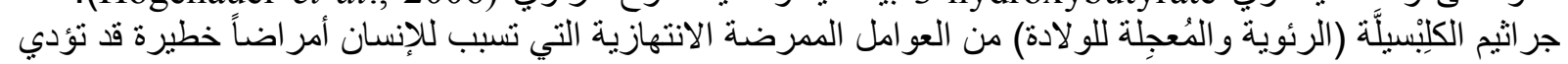

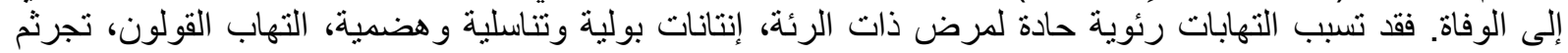
الدم Bactermia، وفي حالات نادرة تسبب التهاب السحايا (Rodrigues, 2008).

\section{MATERIALS and METHODS \\ مواد البحث وطرائقه}

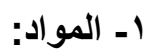

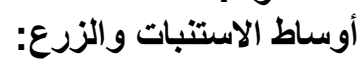

ماء البيتون الموفي BPW) Buffered Pepton Water)، وسط ايوسين ميثيلين بلو آجار Eosin Methylen blue) Agar (EMB) Agar

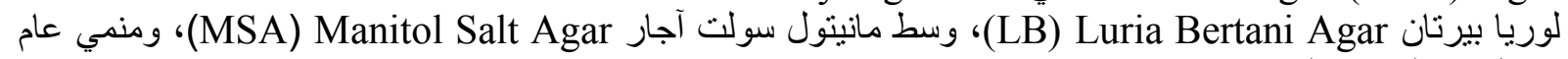
مع الصاد الحيوي الفانكومايسين (LB+Van 25 mg/ml).

مواد الاختبارات الحيوية الكيميائية:

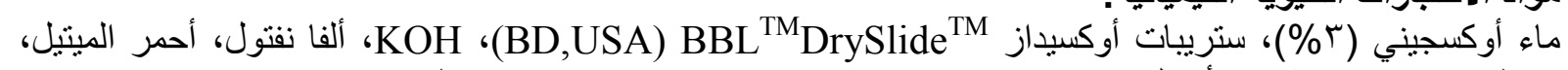

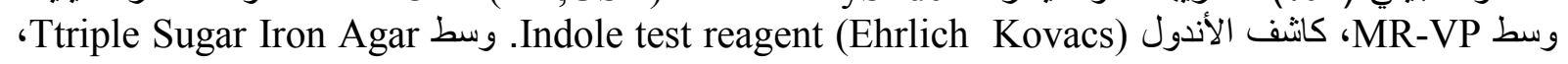


وسط Simotility

Tetrazolium Salts citrat ، أملاح التترازوليوم.

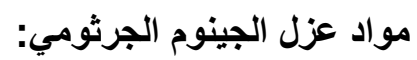

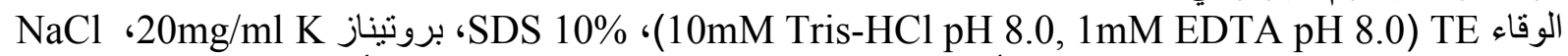

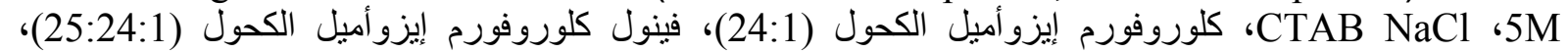
إيزوبروبانول، إيتانول 70\%.

مواد التفاعل السلسلي للبوليميراز والرحلان: وقاء 200mM Tris-HCl pH8.8, 100mM KCl,100mM (NH

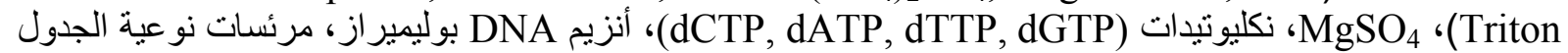

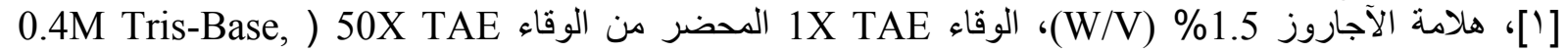
.(10mM EDTA pH 8.0, $57.1 \mathrm{ml}$ Glacial Acetic Acid

مادة الحفظ: غليسيرول 50\%.

r r r الطرائق:

بلغ عدد العينات ل . . 1 عينة، من اللحوم (عجل، ضأن، دجاج). وقد جُمِعَت من مناطق مختلفة من دمشق وريفها.

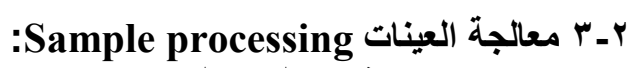

بعد بعد سحق 0.5 غعالجة العن العن العينة المدروسة:

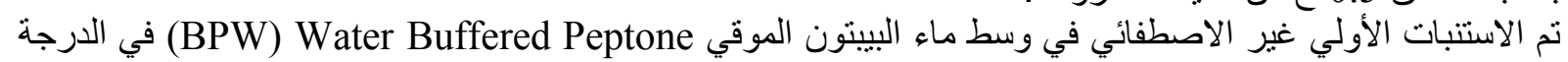

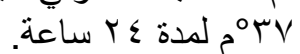

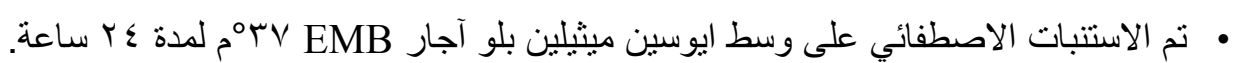

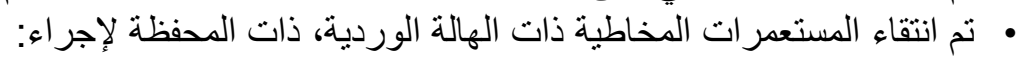

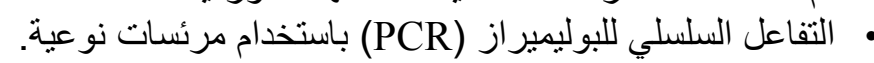

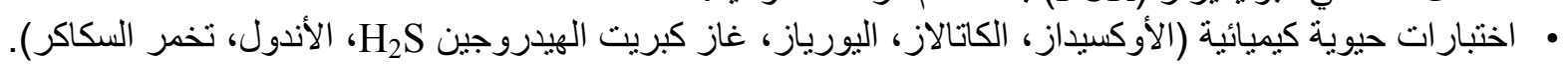

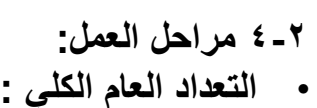

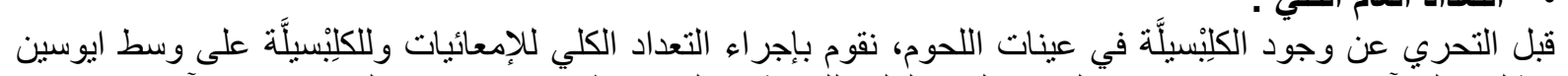

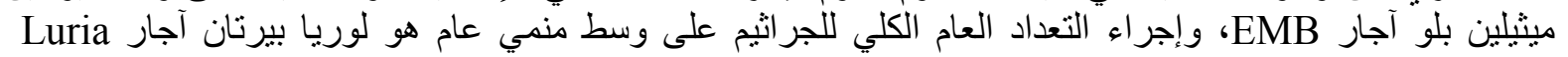

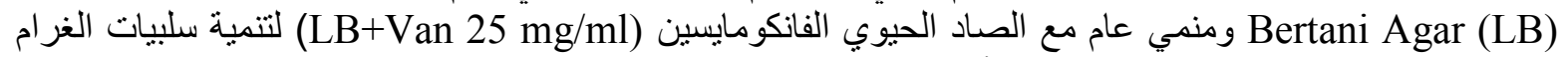
دون ايجابيات الغر ام، ووسط مانيتول سولت آجار (MSA) Manitol Salt Ägar لتنمية ايجابيات الغر ام.

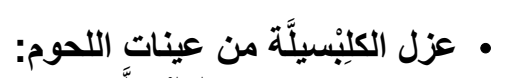

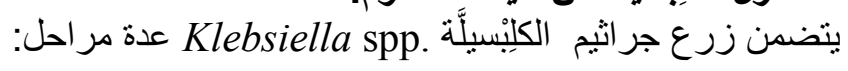

ا- مرحلة الاستنبات الأولي: تم سحق 0.5 غ من العينة وتتميتها في 4.5 مل من ماء البيتون الموقي (BPW) بالدرجة

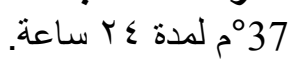

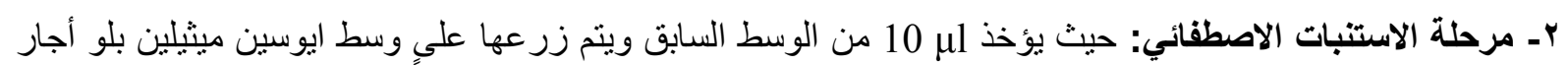

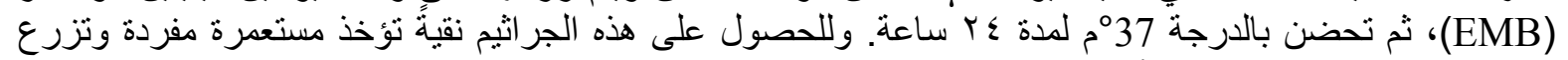
فلى وسط ايوسين ميثيلين بلو آجار (EMB) ونكرر هذه العملية حتى نحصل على طلى طبق يحوي مستعمر ات نموذجية

r- توصيف المستعمرات Colony characteristics

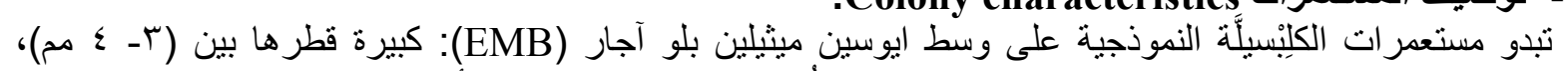
محدبة الثكل، مخاطية، غامقة بنفسجية ذات هالة وردية. تُنتقى هذه المستعمر ات من أجل أجل تلوينها. 
ا ا. يُغمر المحضر بمحلول البلورات البنفسجية لمدة •ب ثانية.

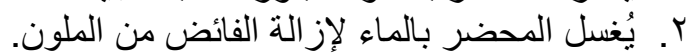

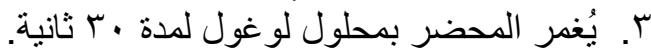

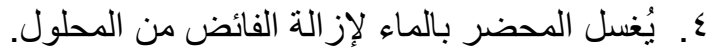

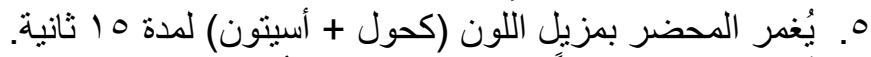

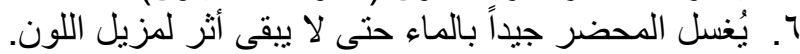

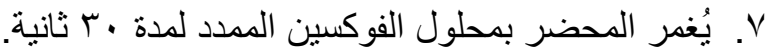

1. يُغسل المحضر بالماء ويُجفف، ويُفصص تحت المجهر باستخدام العدسة الغاطسة.

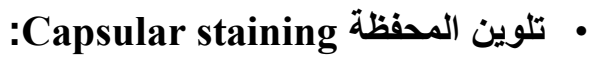

ا. يُحضر الغشاء الجرثومي ويثبت بالطريقة المعتادة (استخدام الكحول مع تجنب استخدام الماء) -لأن المحفظة تذوب بالماء. يُغمر الغشاء بمحلول • بَّ من صبغة الفوكسين القاعدية، وتُمرر الصفيحة فوق اللهب حتى يبدأ الملون بالتبخر.

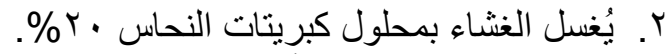

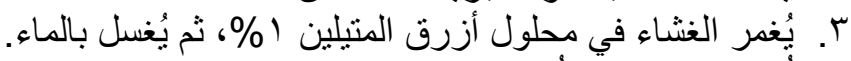

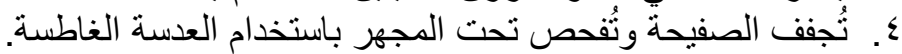

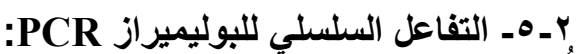

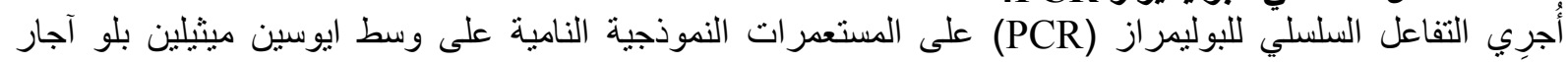
(EMB)

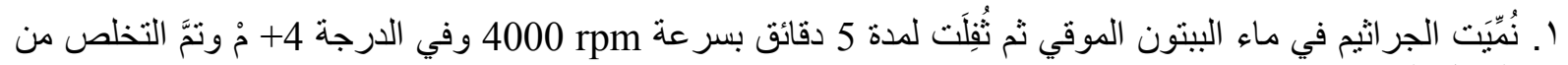

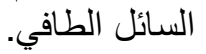

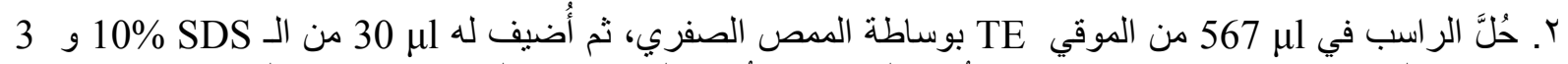
بl من الـ .rpm

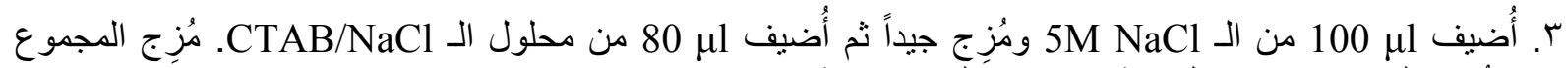

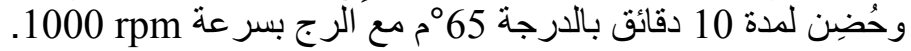

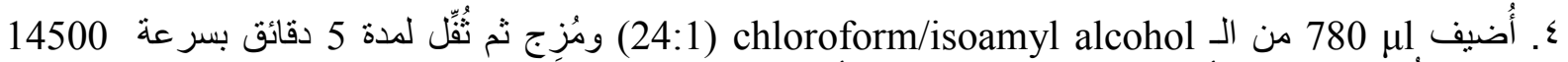

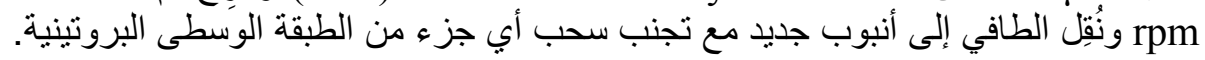

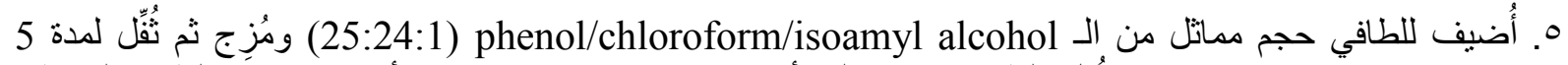
دقائق بسرعة 14500 ونُقِّل الطافي بعدها إلى أنبوب جديد مع تجنب سحب أي جزء من الطبقة الوسطى

البروتينية.

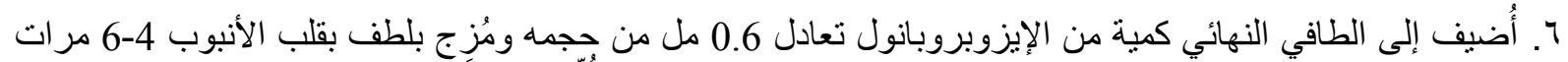

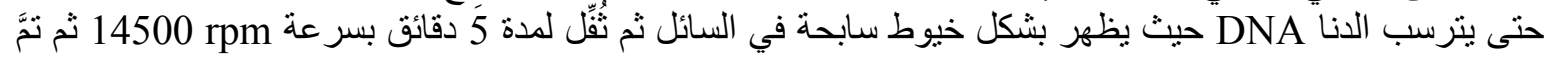

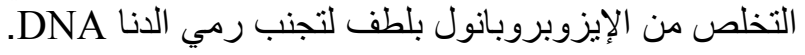

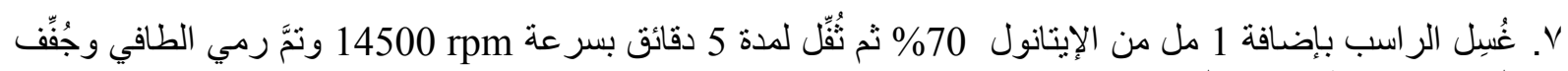

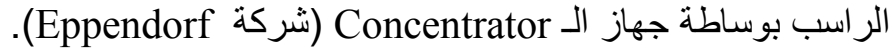

^. نُّ حل الر اسب الناتج في 25 من من الموقي TE ثم قِيس تركيزه بوساطة جهاز المطيافية (Nano Drop) ومُدِّد

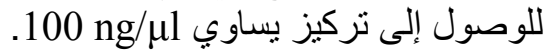

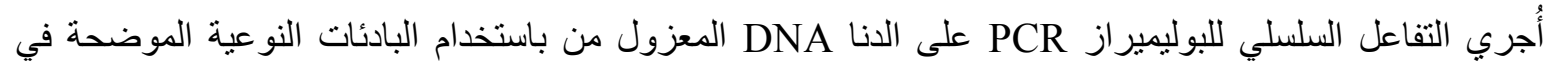

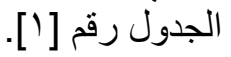

الجدول رقم 1: البادئات النو عية المستخدمة لجنس الكلِبِسيَّة.

\begin{tabular}{|c|c|c|}
\hline & التسلسل Sequence & الحجم \\
\hline Klebrib-1 & 5'- GTAATGTCTGGGAAACTGCC-3' & \multirow{2}{*}{$1500 \mathrm{bp}$} \\
\hline Klebrib-2 & 5'- ССАССТТССТССAGTTTATC-3' & \\
\hline
\end{tabular}


أُجري التفاعل بحجم 25 ويوضح رقم [2] المواد المستخدمة في التفاعل، في حين يوضِّح الجدول رقم [3] الشروط

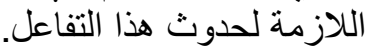

الجدول رقم ؟ : المو اد المستخدمة في تفاعل الـ PCR

\begin{tabular}{ccc}
\hline Materials & Final conc. $\mu 1$ & $25 \mu 1$ PCR \\
\hline Genomic DNA & $200-500 \mathrm{ng}$ & $\bullet \mu 1$ DNA (100 ng) \\
\hline Primer $1-10 \mu \mathrm{M}$ & $20 \mu \mathrm{M}$ & $1 \mu 1$ \\
\hline Primer $2-10 \mu \mathrm{M}$ & $20 \mu \mathrm{M}$ & $0.5 \mu 1$ \\
\hline dNTPs $20 \mathrm{mM}$ & $0.4 \mathrm{mM}$ & $2.5 \mu 1$ \\
\hline Buffer $10 \mathrm{X}$ & $1 \mathrm{X}$ & $1.5 \mu 1$ \\
\hline $\mathrm{MgSO} 450 \mathrm{mM}$ & $3 \mathrm{Mm}$ & $0.2 \mu 1$ \\
\hline Taq $5 \mathrm{U}$ & $2 \mathrm{U}$ & $16.3 \mu 1$ \\
\hline $\mathrm{H}_{2} \mathrm{O}$ & ---- &
\end{tabular}

الجدول رقم ب: شروط تفاعل الـ PCR

\begin{tabular}{|c|c|c|c|}
\hline & & ل درجة الحرارة & الزمن \\
\hline & Initial denaturation & $95^{\circ} \mathrm{C}$ & $5 \operatorname{mins}$ \\
\hline \multirow{4}{*}{35 Cycle } & Denaturation & $95^{\circ} \mathrm{C}$ & $30 \mathrm{sec}$ \\
\hline & Annealing & $7 .{ }^{\circ} \mathrm{C}$ & $30 \mathrm{sec}$ \\
\hline & Extension & $72^{\circ} \mathrm{C}$ & $1 \mathrm{~min}$ \\
\hline & Final Extension & $72^{\circ} \mathrm{C}$ & $10 \mathrm{mins}$ \\
\hline
\end{tabular}

ومن ثم نمَّ الكثَف عن نواتج الـ PCR TAE باستخدام هلامة الآجاروز 1.5 \% المحضرة في الوقاء والترحيل على فولطية 85 لمدة نصف سن ساعة.

تمَّ الاحتفاظ بالمستعمر ات المؤكدة في الـ BPW مع الغليسيرول 50\%، ومن ثم حُفِظت بالدرجة -80٪م من أجل الدر اسات

اللاحقة.

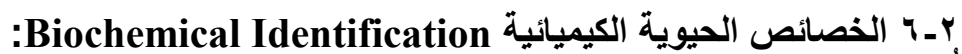

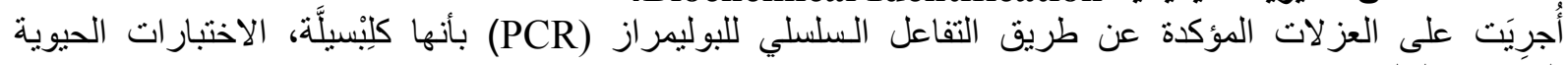
الكيمِيائية التالية:

• اختبار الحركة: أُجري باستعمال الآجار نصف الصلب (وهو ماء البيتون الموفي المضاف إلبه كمية من الآجار)

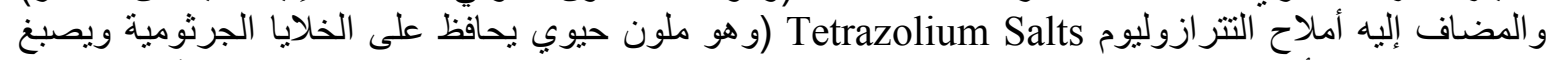

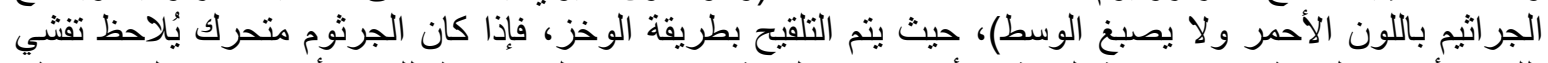

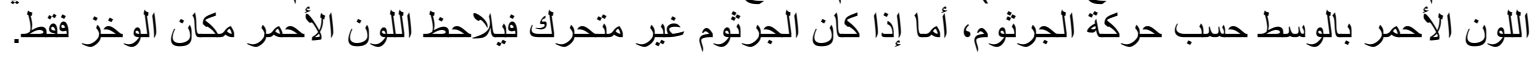
• اختبار الأوكسيداز: أُجري باستعمال ستريبات BDD,USA) BBL

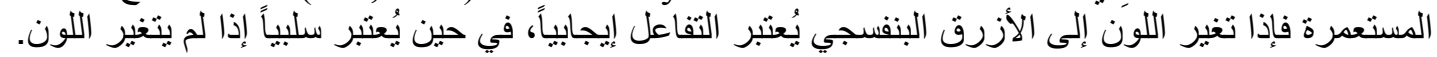

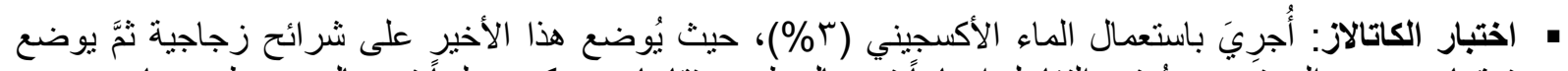

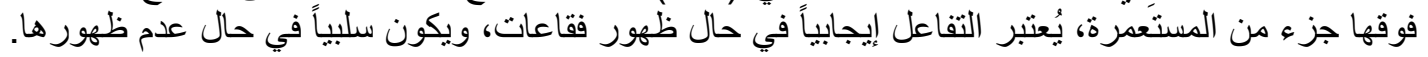

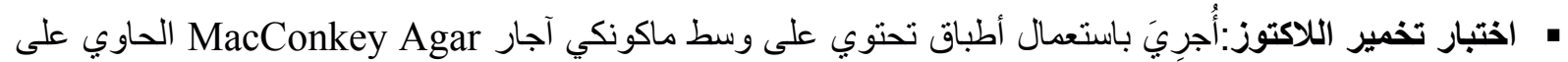

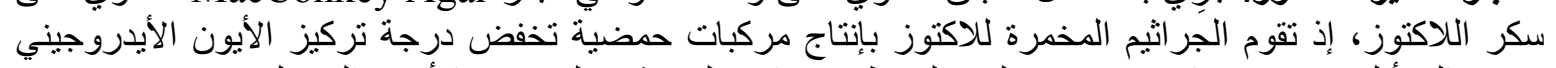

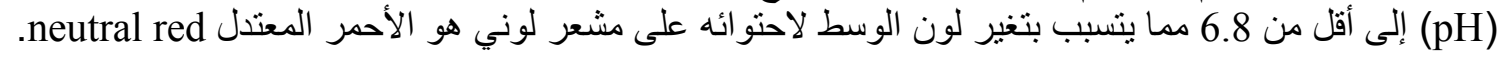

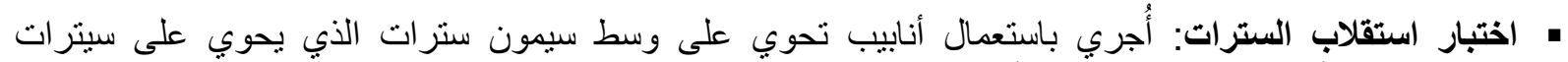

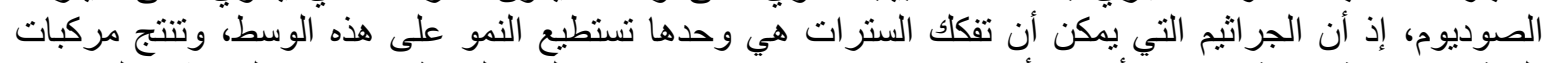

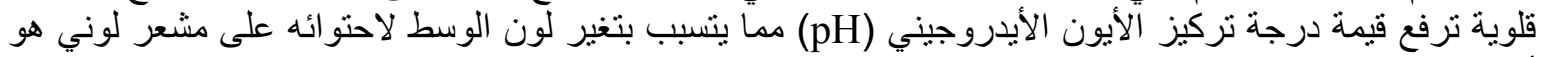

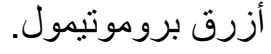


• اختبار حلهة البولة Urease: أُجري باستعمال أنابيب تحوي على وسط اليوريا Urea، إذ تقوم الجراثيم التي إني

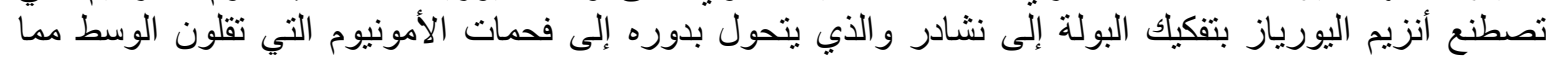

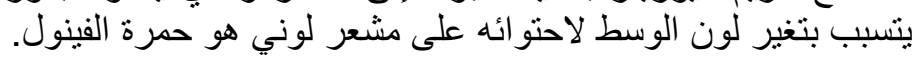

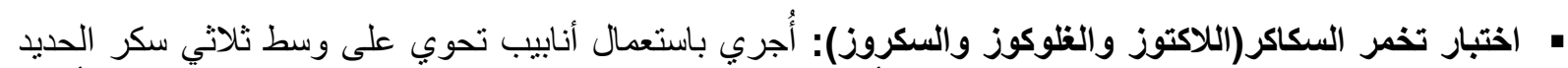
Triple Suger Iron Agar

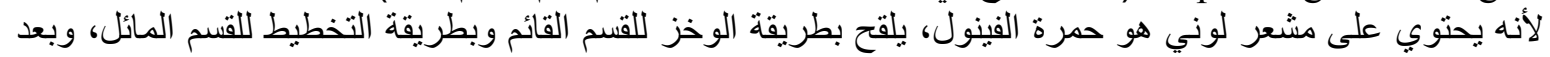

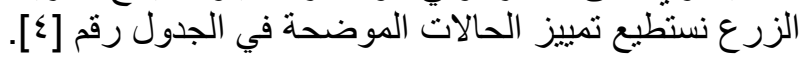

الجدول رقم ؟ : حالات نمو الجر اثيم على وسط ثلاثي سكر الحديد

\begin{tabular}{|c|c|c|}
\hline 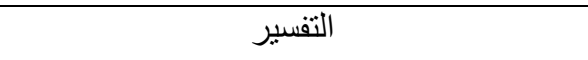 & 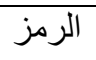 & النتائج (المائل /القائم) \\
\hline تخمر الغلوكوز فقط & $\mathrm{K} / \mathrm{A}$ & أحمر/أصفر \\
\hline تخمر السكاكر الثلاثة & $\mathrm{A} / \mathrm{A}$ & أصفر/أصفر \\
\hline لم يتخمر أب من السكريات الثلاثة & $\mathrm{K} / \mathrm{K}$ & أحمر/أحمر \\
\hline انطلاق غاز أثناء تخمر السكر & $\mathrm{G}$ & حدوث انثقاق بالوسط \\
\hline تحول كبريتات الحديد إلى كبريت الحديد الأسود & $\mathrm{H}_{2} \mathrm{~S}$ & 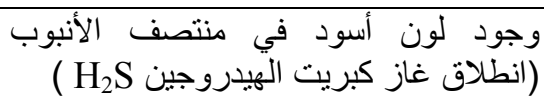 \\
\hline
\end{tabular}

• اختبار إنتاج غاز كبريت الهلروجين H2S:

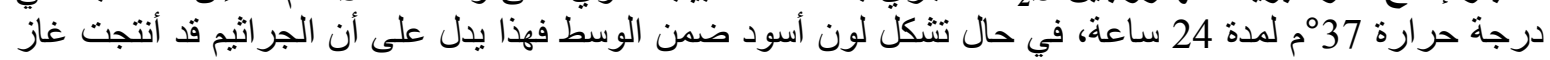
كبريت الهدروجين

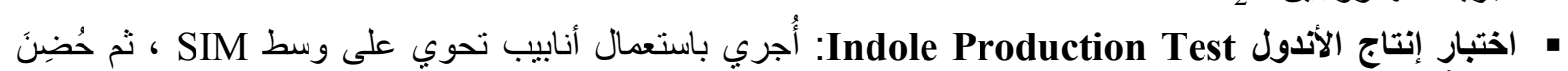

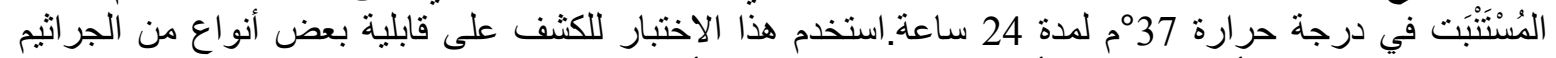

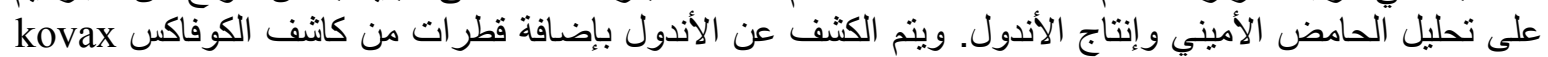

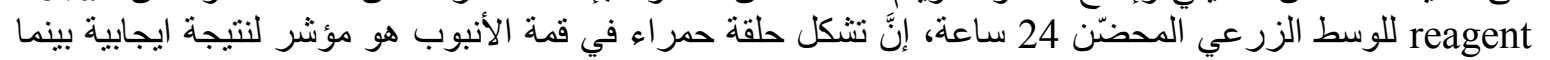
عدم تغير اللون و تشكل حلقة صفر اءو مؤشر لنتيجة سلبية.

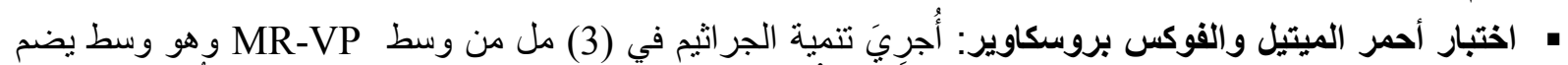

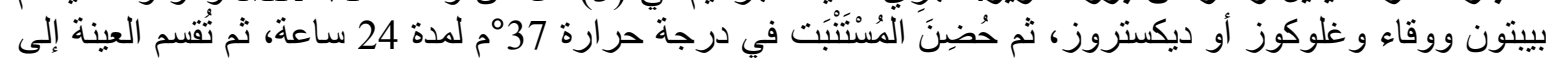

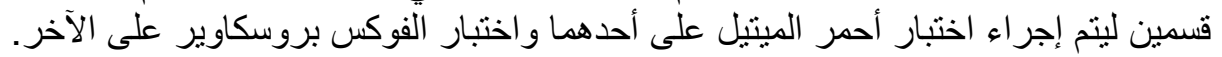

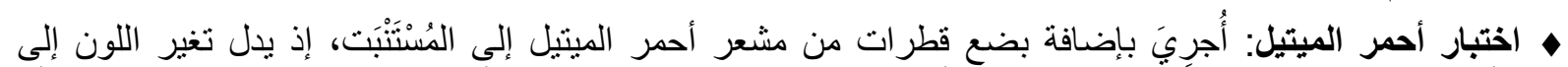

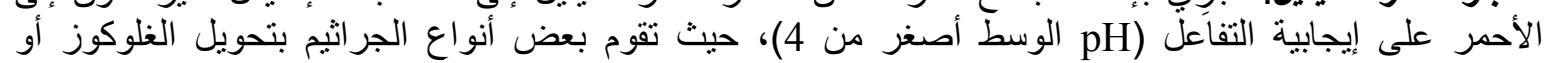

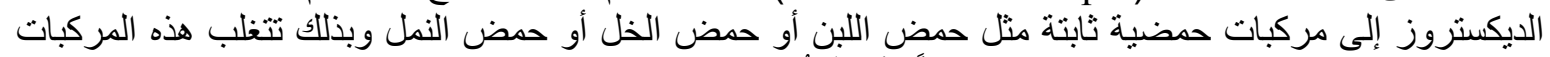

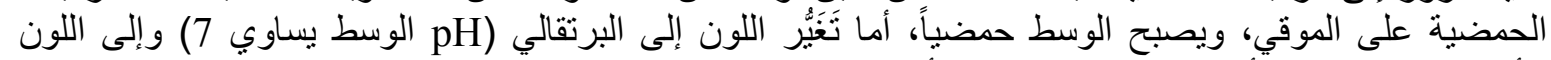

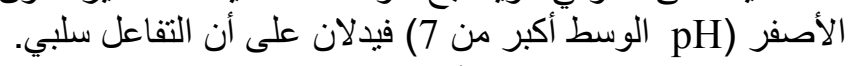

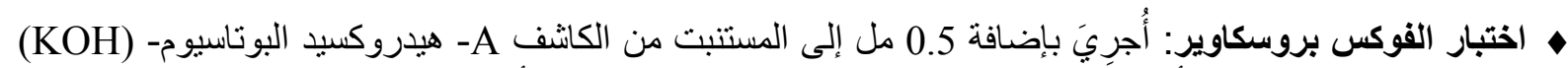

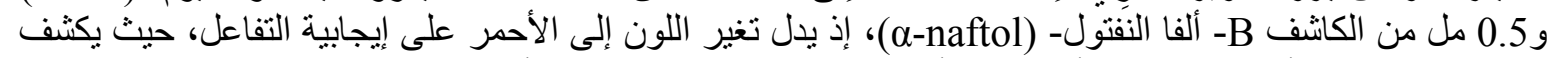

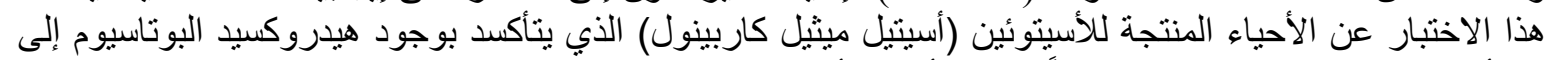

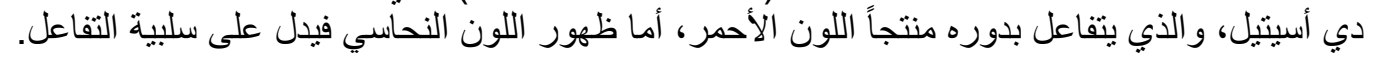

\section{RESULTS and SISCUSSION النتائج والمناقشـة}

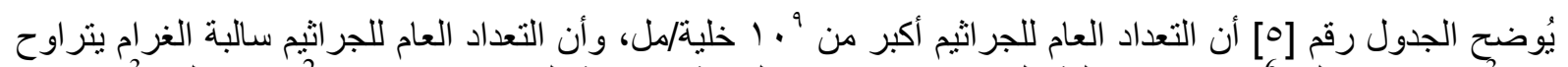

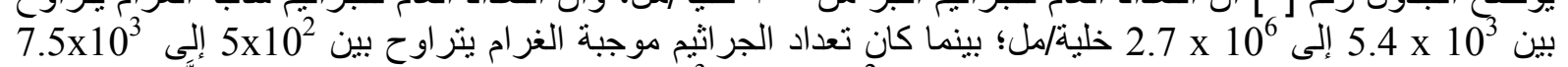
2.5x بلية/مل للعينات المدروسة. كان تعداد الإمعائيات بين

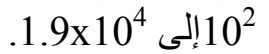


الجدول رقم ه: التعداد العام الكلي للجر اثثم على أوساط مختلفة

\begin{tabular}{|c|c|c|c|c|}
\hline \multicolumn{2}{|c|}{$\begin{array}{c}\text { ايوسين ميثيلين بلو آجار } \\
\text { EMB (cfu/ml) }\end{array}$} & \multirow[t]{2}{*}{ ماتينول سولت آجار } & \multirow{2}{*}{$\begin{array}{c}\text { منمي عام مع صاد حيوي (الفانكومايسين) } \\
\text { LB-VAN (cfu/ml) }\end{array}$} & \multirow[t]{2}{*}{$\begin{array}{l}\text { لوريا بريتان آجار } \\
\text { LB (cfu/ml) }\end{array}$} \\
\hline تعداد الكِلِّبيلَّة & تعداد الإمعائيات & & & \\
\hline $2.5 \times 10^{2}-1.9 \times 10^{4}$ & $5 \times 10^{2}-7.5 \times 10^{3}$ & $5 \times 10^{2}-7.5 \times 10^{3}$ & $5.4 \times 10^{3}-2.7 \times 10^{6}$ & $>19^{9}$ \\
\hline
\end{tabular}

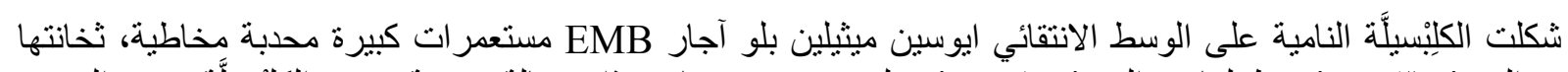

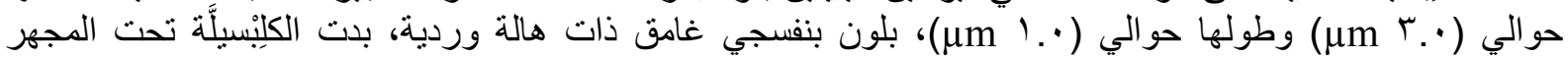

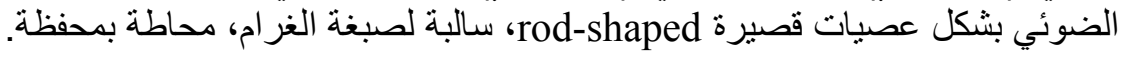

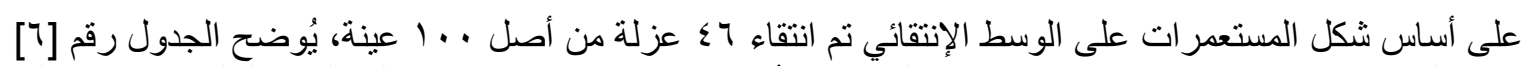

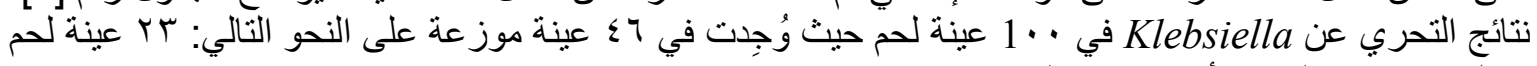
عجل و ـا عينة لحم ضأن و و عينّة لحم دجاج.

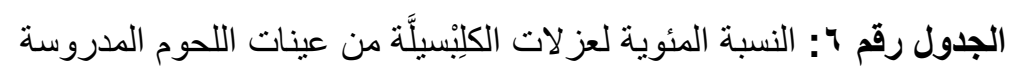

\begin{tabular}{|c|c|c|c|}
\hline النسبة المئوية & عداد عزلات الـ Klebsiella & عدد العينات & المادة الغذائية \\
\hline$\% 70 . V$ & Tr & ro & 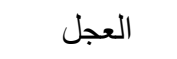 \\
\hline \%46.6 & $1 \varepsilon$ & r. & الضـأن \\
\hline$\% 25.7$ & 9 & To & ال الدجاج \\
\hline
\end{tabular}

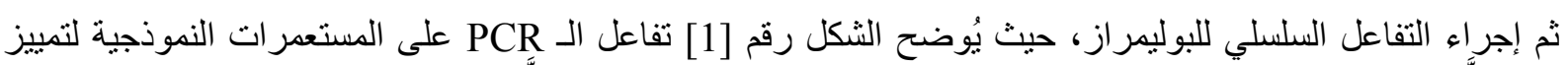

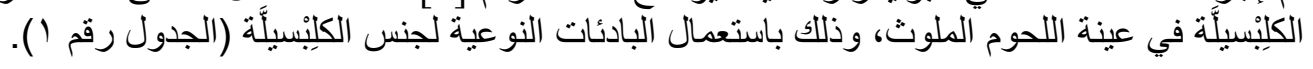




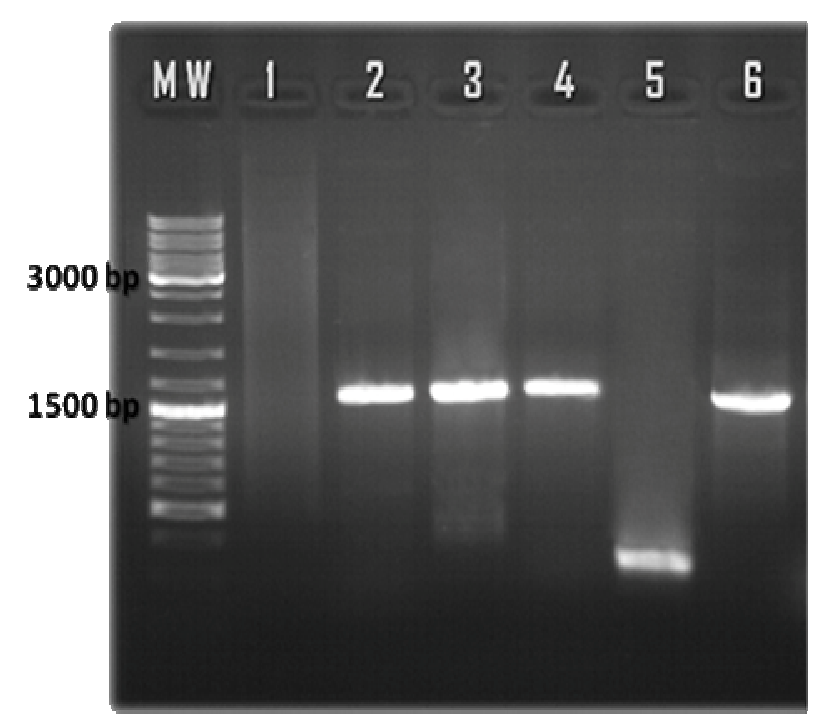

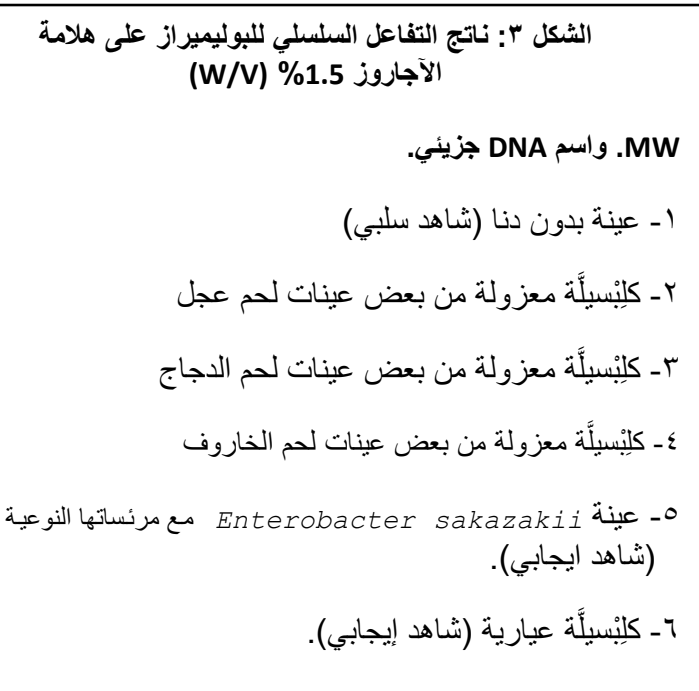

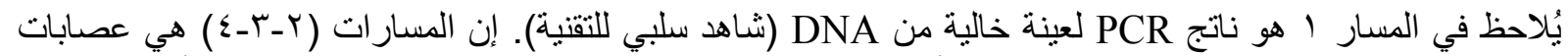

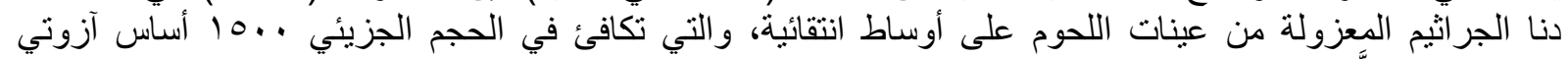

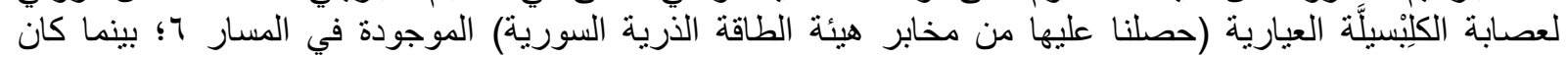

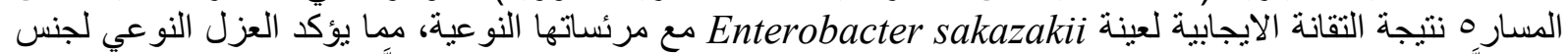

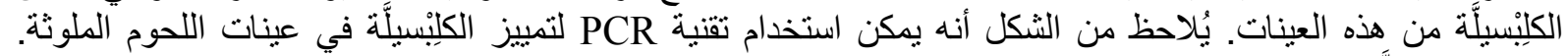

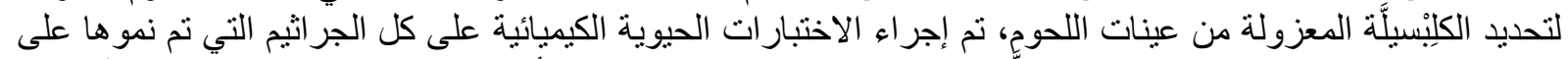

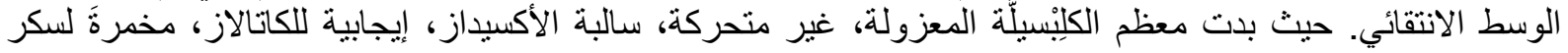

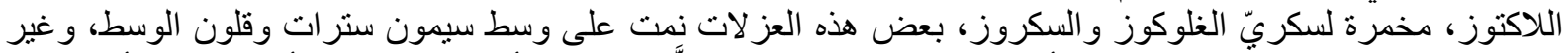

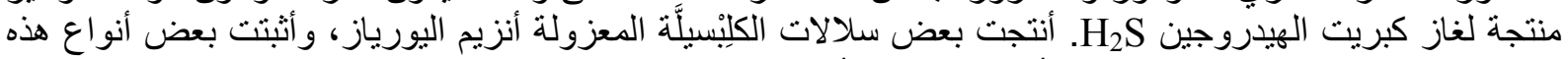

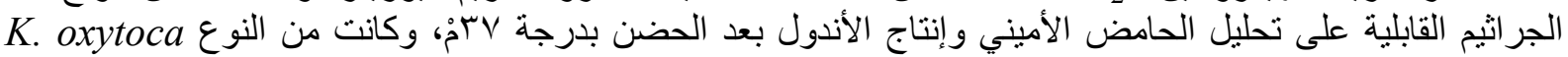

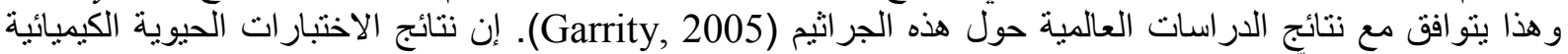

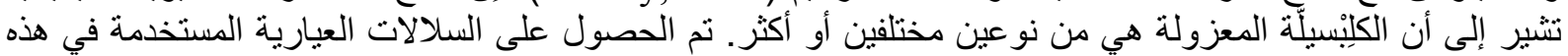

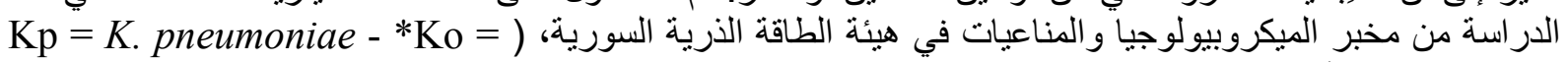
Ko. oxytoca

الجدول رقم V: نتائج الاختبار ات الحيوية الكيميائية للكِلِّبيلَّة

MR VP العينات الحركة الأوكسيداز الكاتال التخمز

\begin{tabular}{|c|c|c|c|c|c|c|c|c|c|c|c|}
\hline+ & - & - & - & $\mathrm{A} / \mathrm{A}, \mathrm{G}$ & + & + & + & + & - & - & $* \mathrm{Kp}$ \\
\hline+ & - & + & - & $\mathrm{A} / \mathrm{A}, \mathrm{G}$ & + & + & + & + & - & - & ${ }^{*} \mathrm{Ko}$ \\
\hline+ & - & + & - & $\mathrm{A} / \mathrm{A}, \mathrm{G}$ & + & + & + & + & - & - & 1) عزلة \\
\hline+ & - & - & - & $\mathrm{A} / \mathrm{A}$ & + & + & + & + & - & - & ا Y عزلة \\
\hline+ & - & - & + & $\begin{array}{c}\mathrm{A} / \mathrm{A}, \mathrm{G} \\
\mathrm{H}_{2} \mathrm{O}\end{array}$ & + & - & + & + & - & + & ع عزلات \\
\hline+ & - & - & - & $\mathrm{K} / \mathrm{A}$ & + & - & - & + & - & - & r عزلات \\
\hline
\end{tabular}

إنَّ الكِلِِسيلَّة واسعة الانتشار، وهي تمتلك اثنين من البيئات، الأول: تكون في البيئة حيث توجد في المياه السطحية، مياه

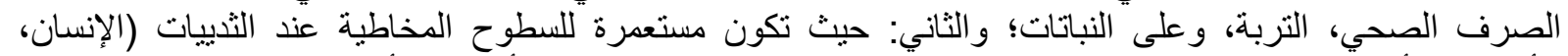

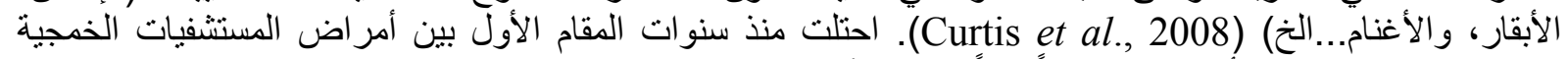
الانتهازية، فهي تستطيع أن تسبب خمجاً تالياً في كل آفة (Maltezou et al., 2009). هنالك اهتمام كبير عند حدوث 


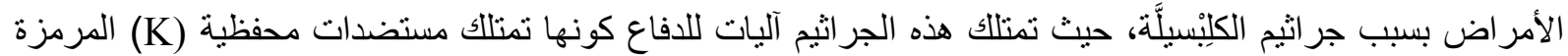

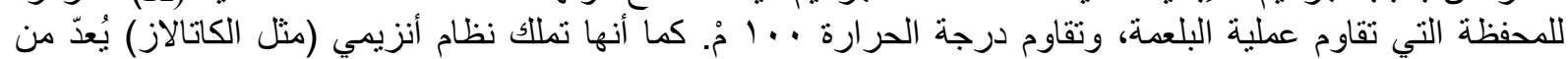

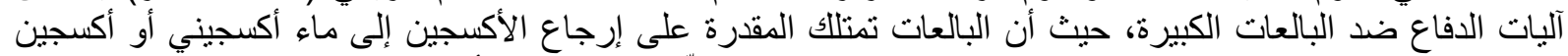

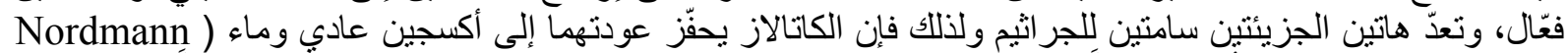

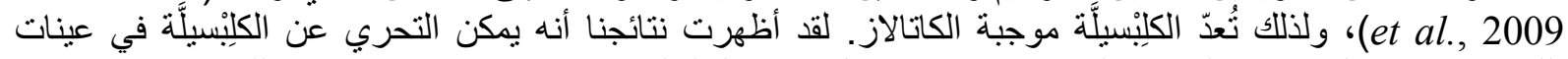

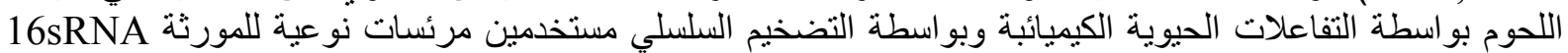

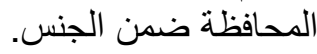

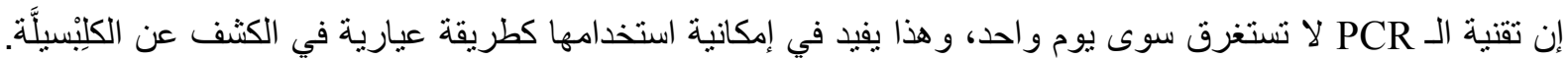

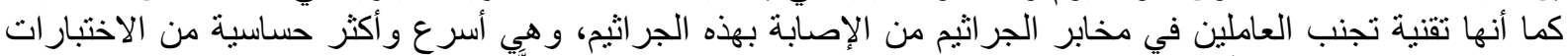

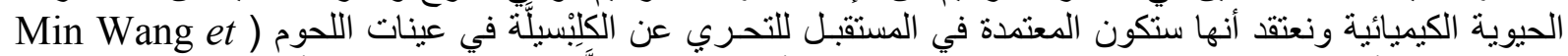

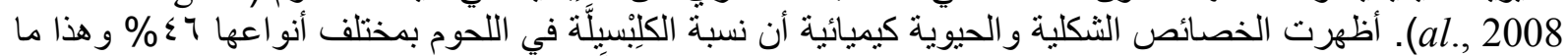

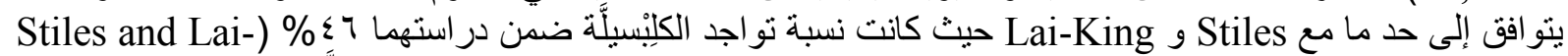

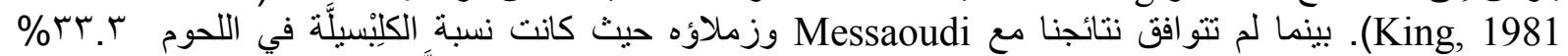
(Messaoudi et al., 2009)

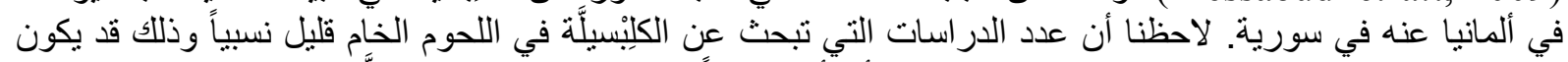

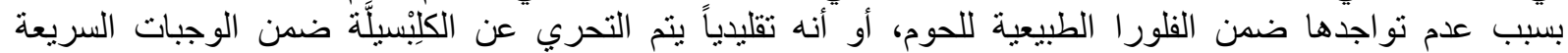

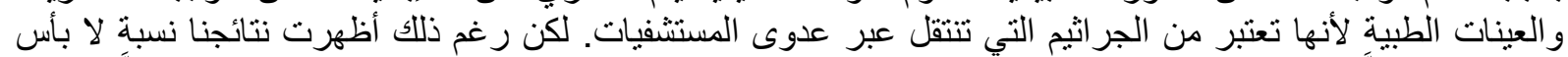

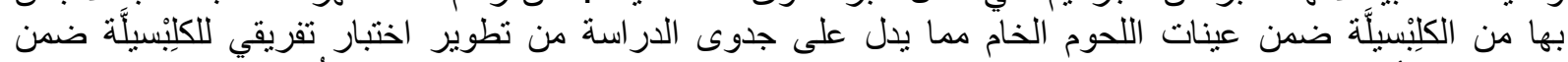

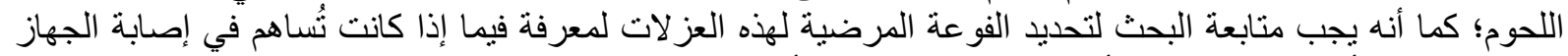

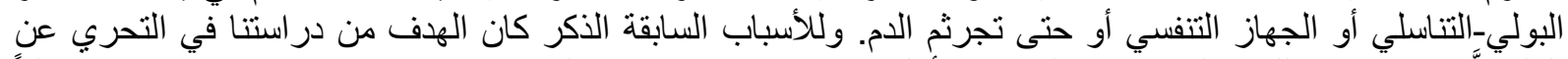

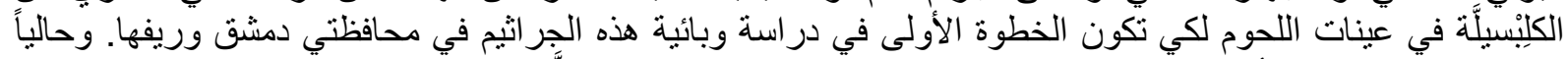

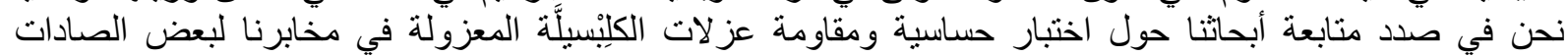
الحيوية المستخدمة في علاج مرضى الالتهابات الرئوية وتحديد فعاليتها في هذه المعالجة التها

\section{الاستنتاجات}

لقد أظهرت نتائجنا أنه يمكن التحري عن الكِلْبسئَّة في عينات اللحوم بواسطة التفاعلات الحيوية الكيميائية وبواسطة التضخيم السلسلي مستخدمين مرئسات نوعية للمورثة 16sRNA المحافظة ضمن الجنة فئس.

\section{REFERENCE}

Anderson, D.J.; Engemann, J.J.; Harrell, Carmeli, L.J.Y.; Reller, L.B. and Kaye, K.S. (2006): Predictors of mortality in patients with bloodstream infection due to ceftazidimeresistant Klebsiella pneumoniae. Antimicrob. Agents Chemother., V. 50, pp. $1715-1720$.

Anonymous, (2002): The cost of antibiotic resistance: effect of resistance among Staphylococcus aureus, Klebsiella pneumoniae, Acinetobacter baumannii, and Pseudomonas aeruginosa on length of hospital stay. Infect. Control Hosp. Epidemiol, V. 23, pp. 106-108.

Augustin, A.; Seng Duong, L.; Kalavsky, E.; Liskova, A.; Kisac, P. and Krcmery, V. (2009): Colonization with cefotazime-resistant Enterobacter spp. and Klebsiella spp. in HIVpositive Cambodian children decreases with immune reconstitution after HAART. $J$. Chemother., V. 21, pp. 232-233.

Bleich, A.; Kirsch, P.; Sahly, H.; Fahey, J.; Smoczek, A.; Hedrich, H.J. and Sundberg, J.P. (2008): Klebsiella oxytoca: opportunistic infections in laboratory rodents. Lab Anim., V.42, pp. 369-375.

Brooks, S.E.; Walczak, M.A.; Malcolm, S. and Hameed, R. (2004): Intrinsic Klebsiella pneumoniae contamination of liquid germicidal hand soap containing chlorhexidine. Infect. Control Hosp Epidemiol., V. 25, pp. 883-885.

Curtis, L.; Nakipoglu, Y.; Kucuker, M.A.; Katranci, H. and Derbentli, S. (2008): Need for more environmental control of Klebsiella and other gram negative infections. Saudi Med J., V.29, pp. 1069. 
Dokladny, K.; Lobb, R.; Wharton, W.; Thomas, Y. and Moseley, P. (2010): LPS-induced cytokine levels are repressed by elevated expression of HSP70 in rats: possible role of $\mathrm{NF}_{-\mathrm{K}} \mathrm{B}$, Cell Stress Chaperones, V.15, pp. 153-163.

Garrity, M. (2005): Bergey's Manual of Systematic Bacteriology. Department of Microbiology and Molecular Genetics, V.2, pp. 716-724.

Guetta, O.; Milas, M. and Rinaudo, M. (2003): Structure and properties of a bacterial polysaccharide from a Klebsiella strain (ATCC 12657). Bio. Macro. Molecules., V. 4, pp. 1372-1379. Handling. Applied and Environmental Microbiology, V.41, pp. 867-872.

Högenauer, C.; Langner, C. and Beubler, E. (2006): Klebsiella oxytoca as a causative organism of antibiotic-associated hemorrhagic colitis. The New England Journal of Medicine. V. 355, pp 2418-2426.

Maltezou, H.C.; Giakkoupi, P.; Maragos, A.; Bolikas, M.; Raftopoulos, V.; Papahatzaki, H.; Vrouhos, G.; Liakou, V. and Vatopoulos, A.C. (2009): Outbreak of infections due to KPC-2-producing Klebsiella pneumoniae in a hospital in Crete. Journal of Infection, V. 58, pp. 213-219.

Messaoudi, A.; Gtari, M.; Boudabous, A. and Wagenlehner, F. (2009): Identification and susceptibility of Klebsiella and Enterobacter spp. isolated from meat products. African Journal of Microbiology Research, V.3, pp. 362-369.

Min Wang; Boyang Cao; Qunfang, Yu.; Lei Liu; Qili Gao; Lei Wang and Lu Feng J Clin. (2008): Microbiol Analysis of the 16S-23S rRNA Gene Internal Transcribed Spacer Region in Klebsiella Species. J.clin. Microbiol., V. 46, pp 3555-3563.

Nordmann, P.; Cuzon, G. and Naas, T. (2009): The real threat of Klebsiella pneumoniae carbapenemase-producing bacteria. Lancet. Infect. Dis., V.9, pp. 228-236.

Rodrigues, P.; Almeida, AM.; Bertoni, BW. And Rclr, P. (2008): Assessment of Genntic relationship between Klebsiella pneumoniae and Klebsiella oxytoca samples isolated from a dental office. J. Venom. Anim. Toxins incl. Trop., V.14, pp. 703-718.

Rosen, D.A.; Pinkner, J.S.; Jones, J.M.; Walker, J.N.; Clegg, S. and Hultgren, S.J. (2008): Utilization of an intracellular bacterial community pathway in Klebsiella pneumoniae urinary tract infection and the effects of FimK on type 1 pilus expression. Infect. Immun., V.76, pp. 3337-3345. Stiles, M. Lai-King, NG., 1981. Enterobacteriaceae Associated with Meats and Meat. 